Available online at GSC Online Press Directory

GSC Biological and Pharmaceutical Sciences

e-ISSN: 2581-3250, CODEN (USA): GBPSC2

Journal homepage: https://www.gsconlinepress.com/journals/gscbps

(RESEARCH ARTICLE)

\title{
Antibiogram of microbial pathogens isolated from drugs sold within Lafia Metropolis, Nasarawa State, Nigeria
}

\author{
Dauda Anoh Hashimu, Joseph Fuh Nfongeh * and Olukayode Olugbenga Orole
}

Department of Microbiology, Federal University of Lafia, Nigeria.

Publication history: Received on 01 August 2020; revised on 19 August 2020; accepted on 23 August 2020

Article DOI: https://doi.org/10.30574/gscbps.2020.12.2.0249

\begin{abstract}
Contamination of drugs by microorganisms may arise during manufacturing, storage or use by the consumers, and can ultimately result in several undesirable consequences. This study was carried out to determine the prevalence of microbial contaminants from commonly administered drugs sold in Lafia Local Government Area, Nasarawa State, Nigeria. Two hundred and forty (240) drug samples comprising 80 samples each from tablets, syrups and ointments were sourced from various outlets and analyzed using aseptic standard culture, and serological methods. The result indicates that $13.75 \%$ of the samples were contaminated. The prevalence of microorganisms isolated among the drugs types include $17(21.25 \%), 11(13.58 \%)$, and 5(6.25\%) for tablets, syrups and ointments respectively. The prevalence of bacterial species isolated from the drugs samples include Escherichia coli (4.58\%), Staphylococcus aureus (3.33\%), Pseudomonas aeruginosa (2.08\%) and Klebsiella pneumoniae (1.25\%), while fungal species include Aspergilus flavus (1.66\%) and Aspergilus niger (0.83\%). Escherichia coli isolated showed resistance to gentamycin 5(45.50\%) and septrin $3(27.30 \%)$, while Staphylococcus aureus isolates showed resistance to septrin 2(25.00\%) and erythromycin 2(25.00\%). The pathogenic and opportunistic pathogens isolated in this study pose a threat to drugs users especially immunocompromised individuals and public health management because the source may not be suspected. Some of the isolates demonstrate multi-drugs resistance to the antibiotics tested. Periodical examination of drugs and antibiogram should be carried out in other to reduce the risk of infections associated with drugs contamination.
\end{abstract}

Keywords: Drugs contamination; Microbial pathogens; Antibiogram; Nigeria

\section{Introduction}

Drugs are used in different ways in the prevention and treatment of diseases and contamination of pharmaceuticals by microorganisms. Irrespective whether they are harmful or non-pathogenic, they can bring about changes in physicochemical characteristics of the drugs [1]. Microbial contamination of drugs results in the spoilage of the formula by breaking down active ingredients and excipients thereby affecting the potency, stability and efficacy of the drug [2]. Furthermore, the presence of high numbers of microorganisms poses a serious health problem to consumers, especially those who are already ill or in a weakened state $[2,3,4]$.

The presence of microorganisms in drugs may lead to undesirable bacterial infections and also the presence of microbial metabolites/toxins may cause serious infections even if they are present in minute amounts. Some of these toxin - related diseases include diarrhea, acute gastroenteritis or abdominal pain [1,5]. Symptoms vary from mild distress to stomach pain and death, depending on the individual sensitivity to toxin, amount ingested, and victim's general health. Severe infections in immuno-compromised people have been assigned to Klebsiella spp. and Bacillus spp. Several hospitals acquired and some outpatient acquired infections, particularly pneumonia, are also assigned to

\footnotetext{
${ }^{*}$ Corresponding author: Joseph Fuh Nfongeh

Department of Microbiology, Federal University of Lafia, Nigeria.
}

Copyright (C) 2020 Author(s) retain the copyright of this article. This article is published under the terms of the Creative Commons Attribution Liscense 4.0. 
Klebsiella spp [1]. Bacteria and fungi are commonly reported to contaminate pharmaceutical products, where contamination with gram-positive bacteria indicate human intervention as reason for contamination. Significantly, the presence of gram negative bacteria suggests lack of process control in the pharmaceutical environments, especially involving water systems and raw materials [3].

The microbiological quality of pharmaceutical products mainly depends on the quality of raw materials, manufacturing process, the environment, the hygienic status of the personnel involved in the manufacture and the storage conditions [6]. Microbes present in drugs do not only make them hazardous from the infectious point but may also change the chemical, physical and organoleptic properties of such drugs or change the contents of active ingredients. Furthermore, microorganisms can convert drugs to toxic products [7]. The occurrence of antimicrobial resistance in bacteria, especially Enterobacteriaceae, is an indication of the emergence of resistant bacterial strains in the community [8].

Drugs resistance is one of nature's never-ending processes where by organisms develop a tolerance for new environmental condition, although, increasing resistance of bacteria to antibiotics due to drug deterioration is well documented [11]. There is therefore the need to know the microbial contents of commonly used drugs sold by pharmacies and hawkers in developing cities due to the lack of adherence to standard health policies. This study is aim at determining the prevalence and antibiogram of microbial pathogens isolated from drugs sold in Lafia, Metroplis in Nasarawa State, Nigeria.

\section{Material and methods}

\subsection{Samples collection}

A total of 240 drug samples comprising of tablets (80), syrups (80) and ointments (80) were collected from hawkers (120) and pharmacy stores (120) in Lafia Metropolis in Nasarawa State, Nigeria.

\subsection{Samples preparation}

Sealed drug samples were collected as packaged by the manufacturers while retailed samples were collected aseptically in sterile plastic containers. The samples were transported in aluminum foil to the Microbiology Laboratory, Federal University of Lafia, for analysis within 6 hrs.

\subsection{Isolation and Identification of colonies}

Each tablet sample was grinded and $1.0 \mathrm{~g}$ of the powdered form dispensed into $9 \mathrm{~mL}$ of distilled water while equal amounts of powdered capsule samples were measured and diluted following same protocol.

For the ointments, $1.0 \mathrm{~g}$ was transferred into $9 \mathrm{ml}$ of distilled water, vigorously shaken and serially diluted to 10-2 while $1.0 \mathrm{~mL}$ of each syrup sample was serially diluted to same dilution factor.

Aliquots of $1.0 \mathrm{~mL}$ from all 10-2 dilutions were dispensed in petri dishes and pour plated with Nutrient agar (Difco) and MacConkey agar (Difco) and incubated at 35oC for 24 hours for bacterial isolation while samples on Sabouraund Dextrose Agar (SDA) (Difco) were incubated at room temperature for 72 hours for fungal isolation.

\section{Identification of Isolates}

Gram staining and biochemical tests were carried out to identify bacterial isolates while fungal isolates were identified based on macroscopic characteristics on SDA and microscopic evaluation on stained lactophenol cotton blue isolates.

\section{Antimicrobial susceptibility testing}

\subsection{Antibacterial susceptibility}

The standard Kirby-Bauer disk diffusion method was used to determine the antimicrobial susceptibility profiles of the isolates. Pure isolates were cultured for antibiotic susceptibility assessment using the disc diffusion method [9]. The pure culture from suspensions were adjusted by using $0.5 \mathrm{McF}$ arland standards and inoculated aseptically on Mueller Hinton agar. Paper discs impregnated with antibiotics were placed on Mueller Hinton Agar and incubated at 37oC for $24 \mathrm{hrs}$. Zones of inhibition were observed and measured after $24 \mathrm{hrs}$ and compared with standard values reported by 
[5]. The antibiotics used in this study were pefloxacin (5 $\mu \mathrm{g})$, gentamycin (10 $\mu \mathrm{g})$, erythromycin $(10 \mu \mathrm{g})$, amoxicillin + calvulalic acid $(10 \mu \mathrm{g})$ and co-trimoxazole $(30 \mu \mathrm{g})$

\subsection{Antifungal susceptibility}

Inoculums were prepared from 1-3 days old cultures on SDA. Suspensions were adjusted by using 0.5 McFarland standards. Using disc diffusion method, the antifungal drugs, Itraconazol (20 $\mu \mathrm{g})$, fluconazole $(25 \mu \mathrm{g})$ and ketoconazole $(20 \mu \mathrm{g})$ were impregnated on paper discs and placed on SDA surface previously seeded with the fungal suspensions [10]. Zones of inhibition were measured and compared with standard values according to [11].

\subsection{Statistical analysis}

Results obtained from this study were analyzed statistically using a one-way ANOVA and Chi-square tools of the Microsoft excel software.

\section{Results}

The prevalence of microorganisms isolated from various types is presented in figure 1 below, E. coli $6.25 \%$, and S. aureus $6.25 \%$, have the highest level of occurrence in tablets and syrups respectively.

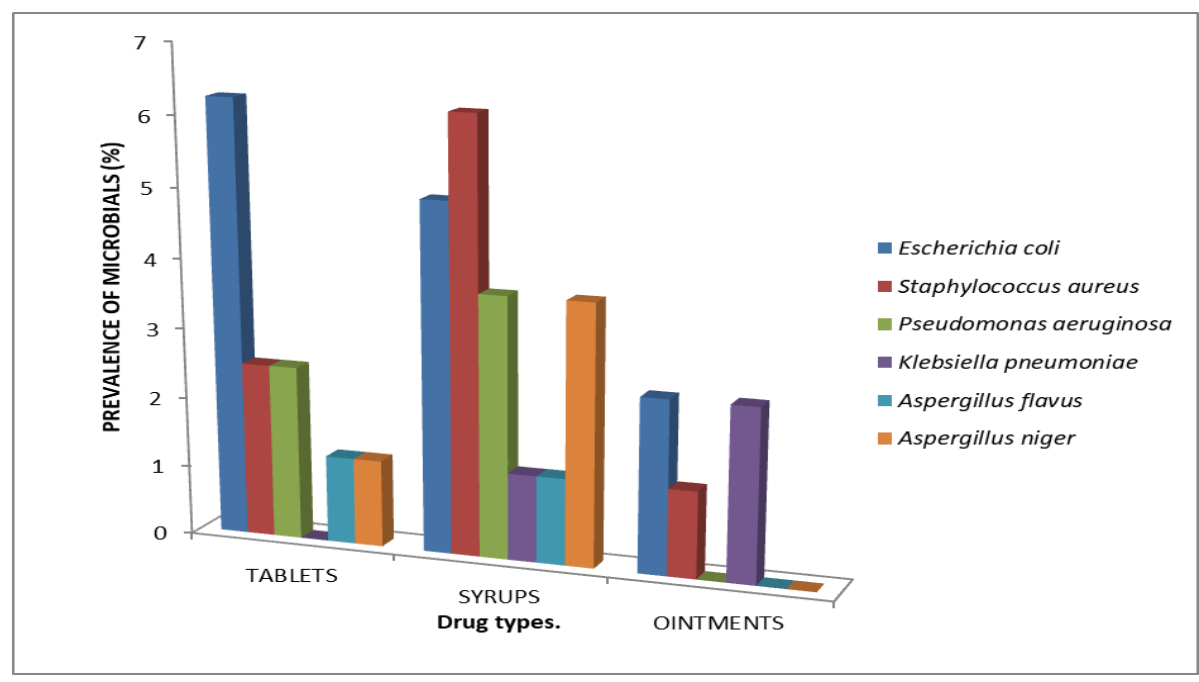

Figure 1 Prevalence of Microbial Species in Various Drugs Types

Figure 2 shows the prevalence of microbial species from drugs with $E$. coli have the highest prevalence $4.58 \%$ while the least is $A$. niger $0.08 \%$.

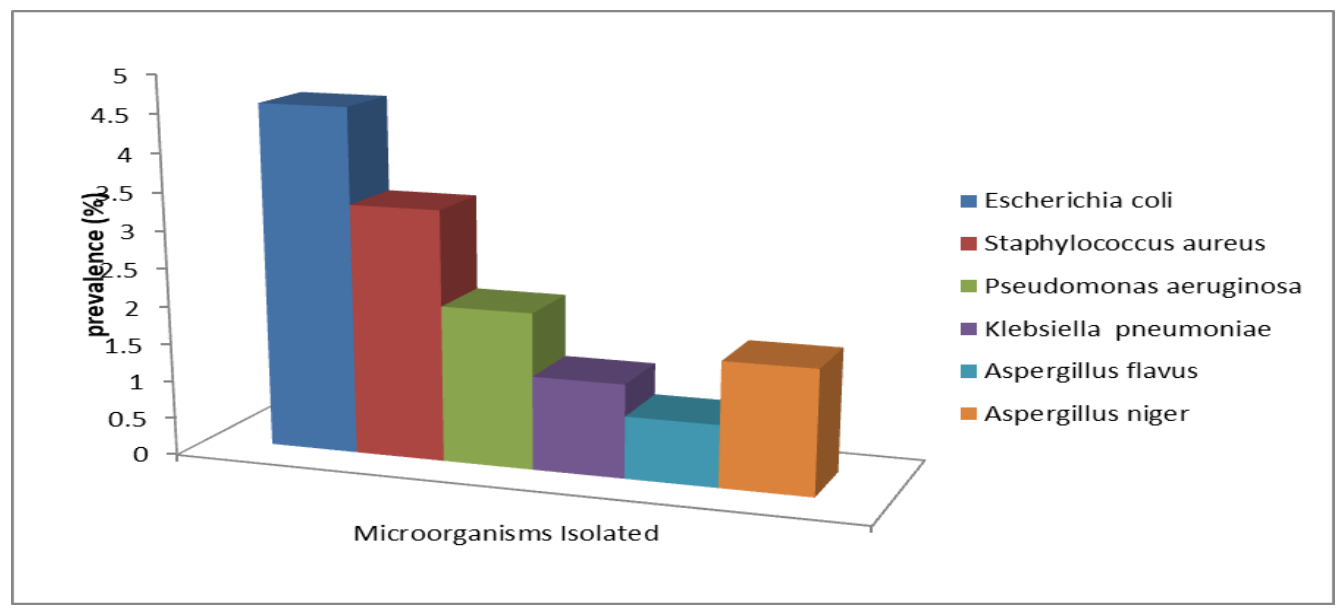

Figure 2 Prevalence of each contaminant from drugs samples examined. 
The occurrence of microbial species in various pharmaceuticals showed that syrups have the highest prevalence of $21.25 \%$ followed by tablets $13.75 \%$, while ointments had $6.25 \%$ as shown in figure 3 .

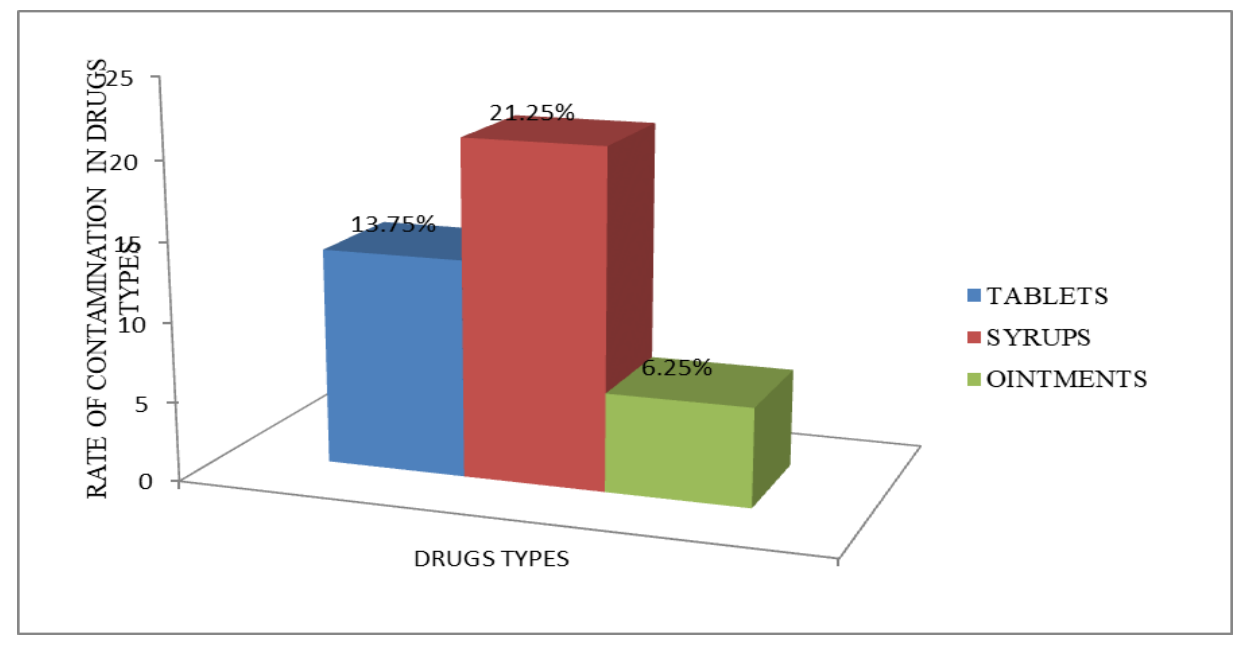

Figure 3 Prevalence of Microbial Contamination per Drugs Types

Table 1 Antibiotics Resistance Pattern of Bacteria Isolated from Drugs

\begin{tabular}{llllllll}
\hline Isolates & $\begin{array}{l}\text { Drugs } \\
\text { Potency }\end{array}$ & $\begin{array}{l}\text { Standard diameter } \\
\text { of inhibition(mm) }\end{array}$ & $\begin{array}{l}\mathbf{E C} \\
\mathbf{n = 1 1}\end{array}$ & $\begin{array}{l}\boldsymbol{S . A} \\
\mathbf{n = 8}\end{array}$ & $\begin{array}{l}\text { PA } \\
\mathbf{n = 5}\end{array}$ & $\begin{array}{l}\text { KP } \\
\mathbf{n = 3}\end{array}$ & $\begin{array}{l}\text { Total } \\
\text { Resistance (\%) }\end{array}$ \\
\hline PEF & $5 \mu \mathrm{g}$ & $<17$ & $(0.00)$ & $(12.50)$ & $(20.0)$ & $(0.00)$ & $(7.40)$ \\
GEN & $10 \mu \mathrm{g}$ & $<12$ & $(27.27)$ & $(0.00)$ & $(60.0)$ & $(33.3)$ & $(25.92)$ \\
ERT & $10 \mu \mathrm{g}$ & $<16$ & $(45.45)$ & $(25.0)$ & $(40.0)$ & $(66.6)$ & $(40.74)$ \\
CTX & $30 \mu \mathrm{g}$ & $<17$ & $(27.27)$ & $(25.0)$ & $(40.0)$ & $(33.3)$ & $(25.92)$ \\
ACA & $10 \mu \mathrm{g}$ & $<17$ & $(0.00)$ & $(62)$ & $(0.00)$ & $(0.00)$ & $(18.51)$ \\
CPF & $10 \mu \mathrm{g}$ & $<14$ & $(18.18)$ & $(0.00)$ & $(20.0)$ & $(0.00)$ & $(11.11)$ \\
\hline
\end{tabular}

$\mathrm{n}=$ number of isolate, $\mathrm{PEF}=$ Pefloxacin; GEN=Gentamycin; ERT=Erythromycin; CTX=Co-trimoxazole; ACA=Amoxicillin+calvulalic acid; $\mathrm{CPF}=$ Ciprofloxacin; $\mathrm{EC}=$ Escherichia coli; $\mathrm{SA}=$ Staphylococcus aureus; $\mathrm{PA}=$ Pseudomonas aeruginosa and $\mathrm{KP}=$ Klebsiella pneumoniae

Table 2 Antifungal Resistance Pattern of Bacteria Isolated from Drugs

\begin{tabular}{|l|l|l|l|l|l|}
\hline $\begin{array}{l}\text { Anifungal } \\
\text { agents }\end{array}$ & $\begin{array}{l}\text { Drugs } \\
\text { potency }\end{array}$ & $\begin{array}{l}\text { Standard zone } \\
\text { of inhibitions }\end{array}$ & \multicolumn{2}{l|}{ Isolates total resistance } \\
\hline & & & AF n-4 & AN n=2 & $\%$ \\
\hline Intraconazole & $20 \mu \mathrm{g}$ & $<20$ & $0(0.00)$ & $1(50)$ & $1(16.6)$ \\
\hline Fluconazole & $25 \mu \mathrm{g}$ & $<20$ & $1(25.0)$ & $0(0.00)$ & $1(16.6)$ \\
\hline Ketoconazole & $20 \mu \mathrm{g}$ & $<20$ & $2(50.0)$ & $0(0.00)$ & $2(33.3)$ \\
\hline \multicolumn{7}{|c|}{$\mathrm{n}=$ Number of isolates; AF= Aspergillus flavus; AN= Aspergillus niger } \\
\hline
\end{tabular}

\section{Discussion}

The results of this study revealed the microbial contents of drugs samples obtained from the study area. From the finding of this work, it could be inferred that low level of contamination $13.75 \%$ of the samples examined were observed. Similar incidence of contamination was documented by [12], where only $13.8 \%$ of the items examined were contaminated. It varies slightly with the report by [13] in Egypt where $10 \%$ of pharmaceutical samples tested were found to be contaminated. However higher incidence was report by [14] where $27.6 \%$ was recorded from samples 
examined. On the drugs types, syrups had the highest level of contamination $21.25 \%$ followed by tablets $13.75 \%$ and ointments $6.25 \%$. Highest value recorded in syrups may be due to the high moisture content of syrups which favors microbial growth and survival.

The bacterial isolated in this study include Escherichia coli, Staphylococcus aureus, Pseudomonas aeruginosa and Klebsiella pneumoniae. This agreed with the report of [10] where all these bacterial species isolated were among the organisms reported. The origin of the contamination may be from poor manufacturing conditions, poor storage and handling. The presence of Escherichia coli in drugs is a good indication of faecal contamination or contamination from hands of personnel involve in the production. Incidence of diarrhoea associated with $E$. coli has been reported in some parts of Nigeria. The presence of Staphylococcus aureus in this study agrees with the finding by [15] and [7] where both group of researchers isolated the organism from drugs. Staphylococcus spp are normal flora of the skin and are usually incriminated as contaminants of production equipment, hands of personnel involved in the production of the product as well as raw materials. Therefore, their probable source in the contaminated drug analyzed could have been one or a combination of these sources. Moreover, the heat resistance of the pathogen and their ability to thrive in fairly high concentration of sugar contributes to their survival in processed products [12]. Its presence in oral products has health implications as the enterotoxin-producing species of the organisms have been implicated in food poisoning [16]. The presence of $S$. aureus in the drugs analyzed is of great concern, as the organism can secretes toxins responsible for gastrointestinal distress. Pseudomonas aeruginosa also isolated in this study, is known to cause opportunistic infections in human and may pose a serious threat to public health. The contamination may be from inadequate storage condition during distribution or packaging.

Severe infections in immunocompromised people have been assigned to Klebsiella spp. Several hospital-acquired and some outpatient-acquired infections, particularly pneumonia, are also assigned to Klebsiella spp. [1]. The isolation of Klebsiella pneumoniae from drugs may be of risk to immunocompromised individuals. Thus its presence in the drugs also indicates unhygienic conditions. Aspergilus flavus and Aspergilus niger were the pathogenic fungal species isolated from the drug samples in this study. This agrees with the findings by [15] in Minna. In addition to Penicilium spp., the presence of these fungi in drugs is a threat to public health as they can cause undesirable effect to consumers of the contaminated products.

The fact that several bacterial species are known to be resistant to a wide array of antibiotics was confirmed by [17]. However, drug resistance as observed in some of the antibiotics used in this study has now become a large and growing problem in treatment of infectious diseases. Therefore, this study can be a guide for use of antibiotics in the treatment of diseases caused by these microbial isolates. The pattern of resistance demonstrated to antibiotics may be due to indiscriminate use of antibiotics by the public. Therefore, the used of these drugs as first line antibiotics against these organisms is not advisable. All E. coli isolates were sensitive to Augmentin and pefloxacin while isolates of Staphylococcus aureus showed resistance to pefloxacin, septrin and augmentin but was sensitive to gentamycin and ciprofloxacin. Most of the isolates showed sensitivity to pefloxacin, ciprofloxacin and augmentin which is in conformity with report by [15].

With the rising frequency of fungal infections, as well as increasing reports of resistance to antifungal agents, it is imperative that clinical applicable antifungal susceptibility testing be available, in order to effectively treat the infection caused by the fungi. In this study, Aspergilus niger isolates were susceptible to ketoconazole and fluconazole while Aspergilus flavus was resistant to fluconazole but were susceptible to itraconazole and ketoconazole.

\section{Recommendation}

Periodical examination of drugs and antibiotic resistance of the isolates should be carried out periodically in other to reduce the risk of infections due to drug contamination. Adherence to good manufacturing practices to prevent contamination and spoilage of the products and possible undesirable effects on consumers is therefore paramount.

\section{Conclusion}

Some pathogenic and opportunistic microbial pathogens were isolated in this study and can pose a threat to drugs users especially in immuno-compromised individuals and those involved in health public health management. Some of the isolates demonstrate multi-drug resistance to commonly used antibiotics though high level of susceptibility was also recorded among other isolates. 


\section{Compliance with ethical standards}

\section{Acknowledgments}

We sincerely acknowledged the contributions from the Laboratory Staff of Microbiology Department, Federal University of Lafia and the Management of Bafawat Biomedical Laboratory, Lafia for their assistance in the laboratory analyses of the samples.

\section{Disclosure of conflict of interest}

The authors whose names are mentioned hereby declare that they have no conflict of interest in this research article and that in case any of such comes up, it will be resolved hitch-free. The authors also declare that this research is solely sponsored by them without any external intervention.

\section{References}

[1] Mugoyela V and Mwambete KD. (2010). Microbial contamination of nonsterile pharmaceutical in public hospital settings. Theatre Clinical Risk Management, 6, 443 - 448.

[2] Campana R, Scesa C, Patrone V, Vittoria E and Baffone Z. (2006). Microbiological study of cosmetic products during their use by consumers: health risk and efficacy of preservative systems. Letters in Applied Microbiology, $43,301-6$.

[3] Jimenez L. (2004). Microbial limits In: Jimenez L, editor. Microbial contamination control in the pharmaceutical industry. Marcel Dekker. New York, 15-44.

[4] Ragheb SM, Yassin AS and Amina MA. (2012). The application of uniplex, duplex, and multiplex PCR for the absence of specified microorganism testing of pharmaceutical excipients and drug products. Journal of Pharmaceutical Science and Technology, 66, 307-17.

[5] Nester MT, Anderson DG, Robert CE and Pearsall NN. (2002). Microbiology. A Human Perspective 3rd ed. MacGraw Hill, Madri Spain, 600-602.

[6] Baird RM. (2004) Microbial spoilage, infection risk and contamination control. In: Denyer SP, Hodges A, Gorman SP, Hugo W and Russells A (eds), Pharmaceutical Microbiology. 17th edn. Blackwell Scientific Publications: London, U.K, 262-284.

[7] Qasem MA, Maissa TS and Walid A. (2014). Microbiological Quality of Blister Pack Tablets in Community Pharmacies in Jordan, Tropical Journal of Pharmaceutical Research, 13(2), 261-266.

[8] Kijima-Tanaka M, Ishihara K, Morioka A, Kojima A, Ohzono T, Ogikubo K, Takahashi T and Tamura Y. (2003). A national surveillance of antimicrobial resistance in Escherichia coli isolated from food-producing animals in Japan. Journal of Antimicrobial and Chemotherapy, 51, 447-451.

[9] Obi CL, Bassey PO and Momba MNB. (2004). Profiles of antibiotic susceptibility of bacterial isolates and physicochemical qualities of water supply in rural Vendor communities. Central Africa Journal of Medicine, 30, 515-520.

[10] Mostafa A, Mohamed TE, Noha E and Walaa E. (2007). Antifungal susceptibility testing: new trends. Egyptian Dermatology Online Journal, 3(1), 1, 1-10.

[11] Clinical Laboratory Standard Institute. (2014). Performance standard for antimicrobial susceptibility testing; 26th Information Supplement, 27, 55-110.

[12] Onurdag FK, Ozgen S and Abbasoglu D. (2010). Microbiological Investigation of Used Cosmetic Samples in Hacettepe Univiversity. Journal of Pharmaceutical Science and Technology, 30, 1-16.

[13] Gad GF, Aly RAI and Ashour MSE. (2011). Microbial evaluation of some non sterile pharmaceutical preparations commonly used in the Egyptian market. Tropical Journal of Pharmaceutiacal Research, 10, 437-445.

[14] Mohammad MA, Rania SE, Walid FE and Nadia AH. (2018). Recovery and Detection of Microbial Contaminants in Some Non-Sterile Pharmaceutical Products. Archives of Clinical Microbiology, 21-26.

[15] Daniyam SY and Sangodere TA. (2011). Microbial assessment of some syrups sold in patent medicine store in Minna metropolis, Nigeria. International Research Journal of Pharmacy, 2(8), 58-61. 
GSC Biological and Pharmaceutical Sciences, 2020, 12(02), 167-173

[16] Obuekwe IF and Obuekwe CO. (2002).Microbial contamination of pharmaceutical products in a tropical environment. Pakistan Journal of Science and IndustrialResearch, 45, 340-344.

[17] Aseffa A, Gedhi E and Asmelash J. (1997). Antibiotic resistance of prevalent Salmonella and Shigella strains in North West Ethiopia. East African Medical Journal, 74, 708-713. 